\title{
Towards a Better Understanding of Climate Change Negotiations
}

\author{
Bryndís Arndal Woods, $\mathrm{PhD}$ student in Environmental Science at the \\ University of Iceland, Dađi Már Kristófersson, Docent of the Economics \\ Department at the University of Iceland and Silja Bára Ómarsdóttir, \\ Adjunct Professor in the Department of Political Science at the \\ University of Iceland
}

\begin{abstract}
The bulk of environmental economics literature applies non-cooperative game theory to examine the stability of International Environmental Agreements. Recently, a new trend has emerged in the literature whereby scholars use modified economic approaches to better account for 'reality' as such. This article builds upon the work of Hugh Ward, Frank Grundig and Ethan Zorick who conducted a mixed-method analysis to create a model of international climate change negotiations which could explain why policy change has been minimal in this issue area. The purpose of this article is to further develop the mixed-method approach in order to gain a better understanding of international climate change negotiations. Using the progression of the 2011 Durban negotiation session as our raw data, we demonstrate the usefulness of conducting qualitative and quantitative analyses simultaneously to best represent reality. Content and discourse analyses are applied to the Durban negotiations to identify the properties of the underlying game. The results are applied to the future of the negotiations in order to identify trends which need to be addressed to reach more progressive outcomes in the future. The main results of the qualitative analyses of the Durban negotiations included that players had modest expectations at the outset of the negotiations, which influenced the issues they addressed. The quantitative analysis demonstrated that players achieved a high degree of success at Durban; all players achieved their desired outcomes on at least half of the issues they addressed. Finally, the mixed-method approach identified important trends from the negotiations, most importantly the cracks exposed within the BASIC bloc and the role of the 'middle ground' alliance.
\end{abstract}

Keywords: Durban Platform, Game Theory, Climate Change Negotiations, Mixed Methods/Integrated Assessment, International Climate Policy. 


\section{Introduction}

The bulk of environmental economics literature uses non-cooperative game theory to examine the stability of International Environmental Agreements (IEAs), most often through the application of complex mathematical models. In the last fifteen years or so, a new trend has emerged in the literature whereby scholars use modified economic approaches to better account for 'reality' as such. This article builds upon the work of Hugh Ward, Frank Grundig and Ethan Zorick (2001) who conducted a mixedmethod analysis by combining a non-cooperative game theoretic approach with regime theory in order to create a model of international climate negotiations which could explain why policy change has been minimal and slow-going in this issue area.

We aim to expand upon previous work within the environmental economics literature by combining a game theoretic approach with a content/discourse analysis of the most recent round of climate negotiations in Durban, South Africa held in November 2011. To the best of our knowledge, this article will be the first to use this particular methodological approach. We attempt to address the narrow focus on solvable mathematical models - which the vast majority of 'traditional' environmental economics literature displays - by demonstrating the usefulness of qualitative analyses to uncover important political dynamics. Ultimately, we deal with the problem of identifying the "true" game being played in climate negotiations by analyzing the most recent round of negotiations in Durban and the political factors which influenced players and their strategies.

The purpose of this article is to gain a better understanding of international climate change negotiations as they currently stand by explaining how and why the Durban negotiations reached the outcome they did and applying the results of the mixed-methodological analysis to the future of these negotiations in order to identify trends and political concerns which hold import for future negotiations. To the best of our knowledge, the methodological approach of this article is a contribution to the field. Our hope is that by combining social and economic methodologies in this manner, we place the focus on the complexities of political processes rather than those of the game model. We maintain that the weakest link in game theoretic analyses of climate negotiations is its representation of reality; players, their strategies and payoffs. Where game theory fails to address the many complexities of climate negotiations, social theory can step in to fill the gap. In this article, we attempt to use a novel mixed-method approach which exposes the value of social theory to uncover political dynamics using discourse and content analysis, and combine those results with the usefulness of game theory for describing how players' strategies interacted to allow for the Durban outcome.

The structure of this article is as follows. We begin with a brief review of the relevant economic and political science literature. The methodological approach is then explained, followed by a brief background of international climate change negotiations. Next, we present a summary of the Durban negotiations including the decisions taken and important turning points at the conference. Subsequently, the results of the content/discourse analyses are presented, including the list of players 
and negotiation issues under analysis. Economic game theory is then applied in order to describe player strategies and measure their degree of success in the negotiations. The discussion section presents and analyzes players' discourses post-Durban in order to demonstrate the usefulness of combining qualitative and quantitative analyses to uncover important 'hidden' dynamics. Finally, the results are interpreted and analyzed to generate predictions and recommendations regarding the future of these negotiations.

\section{Literature Review}

\subsection{Game Theoretic Analyses}

In recent years, the bulk of environmental economics literature on climate negotiations has dealt with the formation of IEAs and the problems of forming coalitions. The contributions in the field of economic game theory can be broadly divided into three categories: the 'traditional' economic approach, the 'modified' economic approach, and the mixed-method approach. The 'traditional' approach is characterized by the use of Integrated Assessment Models and a narrow focus on solving mathematical problems (For example, Carraro, Eyckmans and Finus, 2005; Osmani, 2011). The 'modified' approach is characterized by attempts to update game theoretic models in order to better account for important 'realities', for example by relaxing economic assumptions or adding moral assumptions into economic models (For example, Eyckmans and Finus, 2003; Eyckmans and Kverndokk, 2009; Chou and Sylla, 2008). Finally, the mixed-method approach accounts for 'reality' by combining game theory with an entirely different approach, for example, Ward, Grundig and Zorick combine game theory with regime theory (2001). These categories reflect a trend whereby scholars have begun to critique and modify the 'traditional' approach in order to better account for important political and behavioral dynamics. Game theoretic analyses of climate change negotiations possess significant value and uncover important truths but have limited ability to represent reality in its full complexity.

\subsubsection{The Mixed-Method Approach}

Though the game theoretic literature is vast, this article will address the mixedmethod approach exclusively because we adopt a very similar focus to that of Ward, Grundig and Zorick, who provided one of the few examples of a truly mixedmethod approach to analyzing climate negotiations. In their article, they build on the work of Putnam (1988) by combining a two-level non-cooperative game with regime theory in order to create a model of climate negotiations. Their model treats players as either leaders or veto players, where leaders do not possess a veto. All actors are concerned with policy outcomes in a "single dimensional issue space," where the status quo is the origin (Ward, Grundig, \& Zorick, 2001, p. 442). A veto is assumed to block any proposal which has a lower utility than the status quo. The win-set is defined as all the proposals that will not be vetoed by any of the veto players (stable IEAs). Finally, leaders can use their 'political capital' to influence veto players in either a conservative or progressive direction. 
After running their model in a number of simulations, Ward, Grundig and Zorick proposed four hypotheses: (1) veto players have disproportionate influence due to the fact that one veto can block change, so all veto players must sanction progress; (2) the veto player most resistant to change will receive the highest side payments in an attempt to bring them on board; (3) veto players less resistant to change than the most resistant have a much lesser chance of receiving side payments; and (4) leaders may lobby in a more conservative or more progressive direction than they actually desire as a result of the anticipated actions of other players (Ward, Grundig, \& Zorick, 2001).

Ward, Grundig and Zorick concluded with a discussion of how their model can be used as a descriptive framework to describe the results of the Kyoto negotiation round, which they maintained conformed largely to their predictions. In the case of the Kyoto negotiations, the authors classified the EU and the US as the leaders, although they noted that the EU was by far the most progressive player. The biggest veto player was the US business lobby and other veto players included the poorer members of the EU, the organization of petroleum exporting countries (OPEC), and former Soviet Union states. The authors maintained that the EU was forced to use its political capital and make side payments such as creating a provision for the flexibility mechanisms in order to get veto players to accept the most conservative of the progressive positions, which was that of the US. Ultimately, the end result (the Kyoto Protocol) was very close to the US ideal (Ward, Grundig, \& Zorick, 2001).

\subsection{Discourse and Content Analyses}

Although discourse analysis has traditionally been associated with the study of linguistics and content analysis has likewise been associated with journalism and communications, they have both taken on a social orientation since the 1980s (Antaki, 2008). There are a full range of methods available, none of which claim general veracity; the particular methodology used will vary depending on the intent of the researcher and the parameters within which the analysis will take place (Doulton \& Brown, 2009). In general, discourse analyses attempt to understand text within a broader context so as to understand its non-literal meanings and social consequences (Antaki, 2008). Content analysis is slightly more restrictive than discourse analysis because it involves more specialized and systematic methodological procedures.

Although they are separate methodological approaches, it is common practice to conduct discourse and content analyses simultaneously. This paper employs a broad methodological approach where the two approaches are combined, however, the analytical focus remains on the content analysis technique whereby texts are classified, tabulated and evaluated for their key symbols and themes in order to deduce their meanings and probable effects (rather than the discourse analysis technique of searching for non-literal meaning, which would be a topic for another paper) (Krippendorff, 2004). 


\subsubsection{Discourse and Content Analyses of Climate Change}

Content and discourse analyses of climate change often focus on analyzing interpretations of climate change discourse using mass media. Hugh Doulton and Katrina Brown as well as Peter Weingart, Anita Engels and Petra Pansegrau both found that public communications about climate change tend to ignore scientific uncertainties and emphasize "impending catastrophe". Weingart et al., analyzing German mass media, attributed this to the fact that communications about climate change vary among discourses (2000). Doulton and Brown, analyzing UK mass media, maintained that the tendency of the media to sensationalize is problematic because it portrays developing countries as being unable to fend for themselves (2009). Similarly, Carol Farbotko studied Australian mass media and found that the dominant themes of tragedy are problematic because they serve to ignore important alternative discourses, such as the importance of adaptation or the resourcefulness of the developing world (2005). It is important to note that these conclusions depend highly on context; from the perspective of climate negotiations, one would likely reach very different conclusions regarding assistance for developing nations.

One analysis of mass media dealt with climate negotiations specifically; Zixian Gao examined how Chinese and American mass media framed the 2009 Copenhagen negotiations. Gao found that American mass media had more extensive coverage which tended to focus on the scientific aspects of the issue and the responsibility of the developing nations, whereas the Chinese mass media emphasized the political aspects of the issue and the importance of coordinating social development with climate protection (2011). A final article by J. Hoeffman in 2011 was the only article to conduct a content/discourse analysis of climate change which did not use mass media as the primary source of data. Hoeffman studied academic literature and relevant policy documents to examine the progression of climate change cooperation between the EU and India. Similarly to the methodological approach of this paper, Hoeffman used a "pluralist" approach which combined political science theory with a discourse and content analysis in order to gain a "deeper understanding of the motivations of the actors" (Hoeffman, 2011; p.12). Ultimately, he found that cooperation between the EU and India has been steadily increasing because at all levels of decision making, energy concerns have risen on the agenda and provided opportunities for mutual benefits from cooperation.

Unfortunately, to the best of our knowledge, not a single discourse or content analysis described as such ${ }^{1}$ has been performed which utilizes texts from the climate change negotiations as raw data. It is our hope that this paper fills this gap and demonstrates the usefulness of this methodological approach in unraveling many of the political complexities which are essential to understand players' strategies.

\section{Methodology}

We decided to use both content and discourse analyses as complementary methodological approaches to reveal common themes and underlying meanings of the texts from the Durban negotiations. As mentioned previously, content and 
discourse analyses are conducted simultaneously but our objectives remain within the content analysis domain, whereby texts are evaluated for key issues in order to deduce their meaning.

First, we conducted a discourse analysis of the day-to-day events during the Durban negotiations in order to capture the "feel" of the negotiations as they happened in real-time. At the end of each negotiation day, we read detailed summaries of each day's events obtained online from the Earth Negotiations Bulletin (ENB) as well as any news coverage listed on the UNFCCC website in order to identify which issues were stressed, identify important political developments and turning points, and identify which nations and negotiation groups were most active and influential. This analysis enabled us to create our list of primary and secondary players.

Content analysis was useful for systematically coding country's opening statements for references to various issues, in order to deduce which issues were emphasized by which countries and to identify areas of overlap. In this stage of the methodology, we read each player's opening statement in order to compile a list of all issues which were mentioned, determine which issues were stressed by which players, and determined each players position on each issue (i.e. whether the players desired progressive or regressive action). After negotiations concluded, we read through all the official documents from the Durban negotiations including 19 COP (Conference of the Party) decisions and $17 \mathrm{CMP}$ (Conference of the Parties serving as the meeting of the Parties to the Kyoto Protocol) decisions in order to identify the issues on which decisions were taken and whether these decisions were in the progressive or regressive direction. In this stage, a first step was taken towards understanding each player's strategy and it allowed us to see where countries exhibited overlap, helping to identify the issues on which we could expect to see agreement.

In the next stage, we built on the work of Ward, Grundig and Zorick and used a game theoretic approach to create representations of players' strategies by plotting their issue positions on a strategy continuum. After this was completed, we were able to cluster the continuums by issue and compare players' positions to the Durban outcomes. This enabled us to assess which issues enjoyed consensus, which issues were contentious, and the relative success of each player's strategy.

Lastly, we conducted a final discourse analysis of players' reactions to the Durban outcome in order to demonstrate the value of qualitative approaches to uncover and explain vital political concerns which underlie strategy and fall outside the scope of game theoretic approaches.

Our hope is this novel methodological approach facilitates understanding of the circumstances which allowed for the Durban outcome and helps to identify problematic issue areas on which to focus our attention and effort in order to push negotiations in a more progressive direction in the future.

\section{A Brief Background of Climate Change Negotiations}

In 1992, the first international political response to the danger of climate change was made with the adoption of the United Nations Framework Convention on Climate 
Change (UNFCCC) which aimed to stabilize greenhouse gas concentrations in the atmosphere. In December of 1997, ministers from 170 countries met in Kyoto for the $3^{\text {rd }}$ Conference of the Parties to the UNFCCC; their goal was to set legallybinding targets for GHG emission reductions. The outcome of this meeting was the Kyoto Protocol, which required Annex I (developed) nations to reduce their emissions of six major GHGs by 5.2\% between 2008 and 2012 from 1990 baseline levels (Roberts, 2011). The Kyoto Protocol went into effect in 2005 and was a significant achievement that many hoped would be a first step to stricter, more meaningful and more global emission reduction commitments to come. Unfortunately, in the aftermath of the Kyoto Protocol, the global carbon governance system has stagnated.

In 2007, COP 13/CMP $3^{2}$ took place in Bali, Indonesia; a meeting which began to consider long-term issues which had not been previously addressed. These negotiations resulted in the adoption of the Bali Action Plan and Bali Roadmap which served to separate the negotiations process into two tracks: the AWG-LCA and the AWG-KP. ${ }^{3}$ The former was intended to focus on long-term cooperation on issues such as mitigation, adaptation, finance and technology and the latter was intended to focus on the implementation of the Kyoto Protocol and negotiating a successor treaty by the 2009 deadline at COP 15 in Copenhagen (UNFCCC, 2012).

In the run-up to COP 15, the optimistic anticipation was palpable. Unfortunately, the outcome of the Copenhagen negotiations - the Copenhagen Accord - did not achieve the goals it had set out to and is widely perceived as a complete failure. Critics emphasized that the Accord outlined a system for voluntary emissions reductions rather than legally-binding requirements, a successor treaty to Kyoto was not agreed upon, and the final text of the Accord was decided upon last-minute behind closed doors by the US and the BASIC countries: Brazil, South Africa, India and China (Roberts, 2011). For its part, the COP merely 'took note' of the Accord rather than formally adopting it, as was done at Kyoto and Bali (Earth Negotiations Bulletin, 2011).

After the failure at Copenhagen, hopes were not particularly high heading into Cancun in late 2010. However, the Mexican presidency made the wise decision to put aside the most contentious issues and focus on formally adopting elements of the Copenhagen Accord into the UNFCCC on which agreement was high. Parties agreed to establish several new institutions and processes, such as: the Cancun Adaptation Framework and Adaptation Committee, the Technology Mechanism which includes the Technology Executive Committee, the Climate Technology Centre and Network, and the Green Climate Fund which was designated to be the "new operating entity of the Convention's financial mechanism (Earth Negotiations Bulletin, 2011). These agreements demonstrated that the UN multilateral negotiations system could still produce tangible results. However, the most contentious issues - including the option for a legal agreement and the status of the second commitment period of the Kyoto Protocol - were "kicked down the road" to the next round of negotiations in Durban (Roberts, 2011).

In what is referred to as the North-South divide, negotiations have consistently 
boiled down to the differing perceptions of justice, responsibility and capability between developed and developing countries. Within the negotiations process specifically, this divide has generally manifested itself such that developing nations maintain they should be provided with financial assistance in order to adapt to the effects of climate change, from which they suffer disproportionately and are not historically responsible for. On the other hand, developed nations have been unwilling to provide the level of assistance that developing countries seek and advocate that all countries of the world should accept binding mitigation targets while simultaneously taking advantage of flexibility mechanisms that provide a degree of cost-effectiveness and level the playing field within and among markets.

\section{Data}

The data under analysis was a two-week long negotiation session, and it is necessary to give an overview of the Durban negotiation round in order to understand the results which follow.

\subsection{Key Issues}

At the outset, the expectations of players concerning what was achievable at Durban were modest. In their opening statements, players generally set their sights on resolving issues where agreement was high, namely the operationalization of various Cancun objectives. However, certain players, including the EU, Least Developed Countries (LDCs), and the Association of Small Island States (AOSIS) set the bar higher. In addition to the operationalization of Cancun objectives (particularly with respect to finance and the GCF), two other issues dominated at Durban: reaching agreement on the future of the Kyoto Protocol and on a 'roadmap' to strengthen the global climate regime and lay the foundation for a new agreement.

\subsubsection{Turning Points}

The Formal Break-Up of the G77

There have been tensions developing within the G77 bloc for some time because a handful of countries which are still categorized as developing nations are now richer per capita than many developed nations and are among the world's largest polluters. In the lead-up to Durban, these tensions boiled over when the BASIC countries stated their preference to delay any new emission reduction pledges until at least 2020; a very worrying prospect for small island nations and least developed nations. The importance of BASIC speaking publicly as unified negotiation group for the first time at Durban lies in the fact that it helped clearly delineate the lines along which the Durban outcome was to be negotiated (Clark, 2011). BASIC positioned themselves as a collective identity of emerging powers, capable of acting as a counterweight to both the US and the EU. The clear break-up of the G77 allowed its component groupings to state their national interests and place their political capital where they pleased; a change which shifted the geo-political ground on which the negotiations took place. 
At the end of the first week of negotiations, China laid out the conditions under which it would accept a legally-binding climate deal. Though its conditions were nothing new, many observers felt it was noteworthy that China was demonstrating a more savvy public relations approach at Durban, positioning itself as a powerful player in the talks (York, 2011). There were additional signs of China's openness: China allowed top negotiators to give journalists interviews which was a departure from past years, participated in side events, gave speeches, held daily media events and, for the first time ever, set up a "China Pavilion" to promote its national environmental policies (York, 2011).

\section{Indabas and the Role of the South African Presidency}

Indabas - small, informal consultations organized by the South African Presidency were a popular place for problem-solving at Durban. The importance of the Indabas came into clear focus as the final day of negotiations stretched into a marathon negotiation session. As agreement continued to elude the delegates, the COP President suspended the joint plenary and called on delegates to meet in a small Indaba 'huddle' in order to resolve their outstanding issues. An hour later, the delegates had reached a compromise on the text of the Durban Platform.

\section{The European Roadmap}

In order to agree to take on a second commitment period under the Kyoto Protocol, the EU demanded a parallel legal agreement ${ }^{4}$ covering all parties to come into force by 2015 at the latest. The EU's demand for legal parallelism and the Roadmap they championed helped "draft the script for the central plot in Durban by setting out their stall early in the process and offering to do the heavy lifting ${ }^{5}$ to save the Kyoto Protocol within the context of a roadmap that put up a challenge to other parties developed and developing” (Earth Negotiations Bulletin, 2011).

\section{The EU Alliance}

When the EU Roadmap secured high-profile support from the LDCs and AOSIS, the EU was able to claim that they had the support of 120 nations out of the 190 nations present at Durban (Murray, 2011; Krukowska \& Morales, 2011). Knowingly or not, this was brilliant strategy. By creating the alliance, its members effectively identified the "opposition" to a legal outcome: BASIC and the US. The ability of the EU to claim that nearly two-thirds of the world's nations supported their roadmap gave the EU the momentum needed to successfully pressure the "Big Three" - the US, China and India - to reach a compromise in the form of the Durban Accord.

\subsection{The Decisions Reached}

At Durban, the most divisive political issues which had plagued the negotiations throughout included: the length of the second commitment period, sources of funding for the GCF and long-term finance, long-term cooperative action, and the legal standing of the new agreement. Ultimately, agreement was reached on all of 
these issues, although the degree of consensus varied. In total, there were 19 COP decisions and 17 CMP decisions passed. The most notable decision was one commonly referred to as the 'Durban Platform' because it established a working group whose mandate is to begin work immediately "to launch a process to develop a protocol, another legal instrument or an agreed outcome with legal force" by 2015 which includes a raised level of ambition of mitigation pledges, to be implemented from 2020 (UNFCCC Conference of the Parties, 2011). ${ }^{6}$ The Durban Platform also includes provisions for increasing ambition before 2020 (an important second dimension), and it extended the work of the Ad Hoc Working Group on Long-term Cooperative Action by one year in order to meet its mandate. Other notable decisions taken at Durban include:

- Establishment and extension of the second commitment period of the Kyoto Protocol. The second commitment period is to begin on 1 January, 2013 and end either on 31 December, 2017 or 31 December, 2020, to be decided by AWG-KP 17. It was also decided that Annex 1 nations need to convert their emissions reduction targets (from the first commitment period) to Quantified Emission Limitation and Reduction Objectives (QELROs) by 2012 to be considered at AWG-KP 17.

- Operationalization of the Green Climate Fund in 2012. The GCF is meant to support projects, programs and policies in developing countries related to mitigation, adaptation, capacity-building and technology development and transfer. At Durban, countries began submitting pledges in order to reach the goal of mobilizing 100 billion USD by 2020. It was decided that the GCF "will receive financial inputs from developed Parties to the Convention" and "may also receive financial inputs from a variety of other sources, public and private, including alternative sources" (UNFCCC Conference of the Parties, 2011). However, the details remain to be worked out between the COP and the Fund at COP 18.

- Establishment of an Adaptation Committee designed to improve the coordination of adaptation actions on a global scale. The Committee will report to the COP.

- Operationalization of the Technology Mechanism in 2012. The full terms of reference for the operational arm of the Mechanism, the Climate Technology Centre and Network were agreed upon in addition to a clear procedure to select the host.

- Agreement on a registry to record developing country mitigation actions that seek financial support with the purpose of matching these requests with support. The registry will be a flexible, dynamic, web-based platform.

- Agreement that carbon-capture and storage projects will be allowed under the Kyoto Protocol's Clean Development Mechanism.

- Additional agreements on the Standing Committee, ${ }^{7}$ loss and damage, monitoring, reporting and verification (MRV), Reducing Emissions from 
Deforestation and Forest Degradation (REDD+), and National Adaptation Plans (NAPs).

\section{Results and Discussion}

For the sake of simplicity, the results of this study will be presented in separate sections which represent the results of the content analysis, discourse analysis, and game theoretic analysis. However, it should be noted that this is merely an exercise in straight-forward presentation rather than a clear-cut divide between the various approaches. Ultimately, all three approaches were complementary throughout the course of the study; the results from any one approach helped inform the results of the other approaches and shed light on the interpretation of various issues.

\subsection{Defining Players and Issues}

After reading and summarizing the relevant texts from Durban, the first task to be completed was to compile a list of players. For the sake of simplicity, our list of players has been narrowed down to those players whose opinions were most influential at Durban: we do not claim to present an exhaustive list. In order to best represent the variety of interests and strategies, our list includes not only negotiation groups like AOSIS which are strongly concerned about the effects of climate change, but also large industrialized nations like the US and EU, up-and-coming developing nations like India and China, and the least developed nations. In order to capture important political dynamics, the list was separated into primary players and secondary players. We identified primary players as those countries and negotiation groupings which were present at the final negotiating table for the Durban Accord: the US, China, India and the EU. The secondary players are those who were active and vocal at Durban but were not among the players involved in the final, all-important Indaba huddle: AOSIS, LDCs, South Africa, Brazil, ${ }^{9}$ Japan, Russia and Canada.

After reading through each players' opening statement (all of which were available except for Brazil and the US), we identified a total of 24 issues which were mentioned. Since our objective was to deduce which issues countries desired to see progress on internationally, we excluded any mention of the issues which referenced actions being taken domestically. For each player, we then identified how many issues were mentioned total as well as the number of times each issue was mentioned. Finally, we summed up the total mentions of each issue, as well as the total number of countries which mentioned each issue, as seen in Table 1. 
STJÓRNSÝSLA

Table 1. Players and Issues

\begin{tabular}{|c|c|c|c|c|c|c|c|c|c|c|c|c|}
\hline & \multicolumn{4}{|c|}{ Primary Players } & \multicolumn{6}{|c|}{ Secondary Players } & \multirow{2}{*}{ 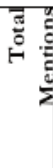 } & \multirow{2}{*}{ 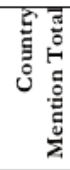 } \\
\hline & China & India & EU & US & $\begin{array}{l}\text { South } \\
\text { Africa }\end{array}$ & Japan & Russia & Canada & AOSIS & LDCs & & \\
\hline $\begin{array}{l}\text { Cancun } \\
\text { Operationalization }\end{array}$ & 4 & & 2 & 2 & 4 & 2 & 3 & 4 & 2 & 2 & 25 & 9 \\
\hline Finance & 2 & & 1 & 1 & 4 & 1 & & & & 5 & 14 & 6 \\
\hline GCF & 1 & 2 & & 2 & 1 & & 1 & 1 & 1 & 1 & 10 & 8 \\
\hline $\begin{array}{l}\text { Technology } \\
\text { Development and/or } \\
\text { Transfer }\end{array}$ & 2 & 1 & & & 3 & 1 & 1 & & 1 & 1 & 10 & 7 \\
\hline Adaptation & 1 & & & 1 & 3 & & 2 & & 1 & 4 & 12 & 6 \\
\hline $\begin{array}{l}\text { 2nd Commitment } \\
\text { Period }\end{array}$ & 1 & 1 & 4 & 2 & 2 & & & & & 2 & 12 & 6 \\
\hline Bali Roadmap & 4 & 1 & & & 1 & & 2 & & & 1 & 9 & 5 \\
\hline Mitigation & & & & 2 & 3 & 2 & & & & 1 & 8 & 4 \\
\hline Transparency & 2 & & 2 & 2 & 1 & & 1 & & & & 8 & 5 \\
\hline Copenhagen & 3 & & 1 & & & & 1 & & 1 & 1 & 7 & 5 \\
\hline Legal Outcome & & 1 & 2 & & 2 & & & & & 2 & 7 & 4 \\
\hline CBDR & 2 & 1 & 1 & & & 1 & & & & 1 & 6 & 5 \\
\hline $\begin{array}{l}2 \text { Degree Warming } \\
\text { Limit }\end{array}$ & & & 4 & 1 & & 1 & & & & & 6 & 3 \\
\hline Equity & 3 & 1 & & & & & & & & 1 & 5 & 3 \\
\hline EU Roadmap & & & 3 & & & & 1 & & & & 4 & 2 \\
\hline MRV & & & 1 & 1 & & & 1 & & 1 & & 4 & 4 \\
\hline Capacity Building & 1 & & & & 1 & 1 & & & & 1 & 4 & 4 \\
\hline $\begin{array}{l}\text { Historical } \\
\text { Responsibility }\end{array}$ & 1 & & & 1 & & & & & & 1 & 3 & 3 \\
\hline NAPs & & & & & 1 & & & & & 2 & 3 & 2 \\
\hline $\begin{array}{l}\text { Flexibility } \\
\text { Mechanisms }\end{array}$ & & & & & & 2 & 1 & & & & 3 & 2 \\
\hline REDD & & & & & & 1 & 1 & & & 1 & 3 & 3 \\
\hline Higher Ambition & & & 1 & & & & & & & 1 & 2 & 2 \\
\hline $\begin{array}{l}\text { Intellectual Property } \\
\text { Rights }\end{array}$ & & & & & 1 & & & & & & 1 & 1 \\
\hline $\begin{array}{l}\text { Polluter Pays } \\
\text { Principle }\end{array}$ & & & & & & & & & & 1 & 1 & 1 \\
\hline $\begin{array}{l}\text { Percentage } \\
\text { Reduction Targets }\end{array}$ & & & & & & 1 & & & & & 1 & 1 \\
\hline
\end{tabular}

It is important to note that the top five issues mentioned most often by the players were almost identical to the top five issues mentioned by the largest number of countries: the operationalization of Cancun objectives, ${ }^{10}$ finance (in general), the GCF (specifically), technology development and/or transfer, and adaptation. However, reference to the second commitment period of the Kyoto Protocol stood in fourth place on the list of issues mentioned most often, whereas it was not among the top five issues mentioned by the largest amount of players. This indicates that although specific players like the EU and G77/China strongly advocated for a second commitment period and mentioned it frequently, the rest of the players did not. These results suggest that players had modest expectations of what was accomplishable 
at Durban. Most players emphasized the operationalization of the various Cancun objectives rather than the more politically divisive issues of the second commitment period or any comprehensive, legally-binding, post-2012 agreement.

\subsection{Applying Game Theory}

In this section, we draw on the work of Ward et al. and represent players' strategies as a continuum where players are concerned with policy outcomes in a single dimensional issue space. The center point of the continuum represents the status quo, points to right represent progressive change and points to the left represent regressive change. However, the purpose of Ward et al.'s article was not to capture the full negotiation process - as is our purpose - but rather to capture the importance of leader players in forging final proposals (Ward, Grundig, \& Zorick, 2001). Thus, our methodology now departs from the framework used by Ward et al. in an effort to explain the political dynamics which allowed for the Durban outcome from a more general point of view.

Of the 24 issues recorded in the opening statements, decisions were ultimately taken on ten. ${ }^{11}$ In order to create the players' strategy continuums, the opening statements of the primary players and secondary players were analyzed for reference to these ten issues, and it was recorded whether they desired progressive action on the issue, moderately progressive action, maintenance of the status quo, moderately regressive action, or regressive action. After this was completed, the Durban outcomes with regard to each negotiation issue were also plotted on the continuums in the regressive, status quo or progressive direction. Creating player strategy continuums in this manner allowed us to identify which issues exhibited high consensus, where players compromised, and which issues were most stressed.

\subsubsection{Strategy Continuums}

Of the ten central issues on which decisions were taken at Durban, nine were addressed by the primary and secondary players. ${ }^{12}$ What follows are condensed strategy continuums, bunched by issue, in order from those with the highest amount of consensus to those with the lowest amount of consensus. ${ }^{13}$

Key:

Original Position

Outcome

Green Climate Fund - Three of the four primary players (U.S., China and India) and five of the six secondary players (AOSIS, LDCs, South Africa, Russia, Canada) desired a progressive outcome on the GCF and a progressive outcome was achieved. ${ }^{14}$ In total, eight out of eight players achieved a satisfactory outcome on the GCF.

\section{Regressive Status Quo Progressive}

MRV - Two of the four primary players (U.S. and EU) and three of the six secondary players (AOSIS, Japan and Russia) desired a progressive outcome on MRV and a 
progressive outcome was achieved. ${ }^{15}$ In total, five out of five players achieved a satisfactory outcome on MRV.

\section{Regressive Status Quo Progressive}

Adaptation - One of the four primary players (China) and four of the six secondary players (AOSIS, LDCs, South Africa and Russia) desired a progressive outcome on Adaptation and a progressive outcome was achieved. ${ }^{16}$ In total, five out of five players achieved a satisfactory outcome on Adaptation.

\section{Regressive Status Quo $\longrightarrow$}

Legal Outcome - Two of the four primary players (India and the EU) and two of the six secondary players (LDCs and South Africa) desired a legal outcome as a part of the Durban package and a legal outcome was achieved. ${ }^{17}$ In total, four out of four players achieved a satisfactory legal outcome.

\section{Regressive Status Quo Progressive}

Technology Mechanism - One of the four primary players (China) and three of the six secondary players (AOSIS, South Africa and Russia) desired a progressive outcome on the Technology Mechanism, and a progressive outcome was reached. One of the four primary players (India) favored a moderately progressive outcome. ${ }^{18}$ In total, four out of five players achieved a satisfactory outcome on the Technology Mechanism.

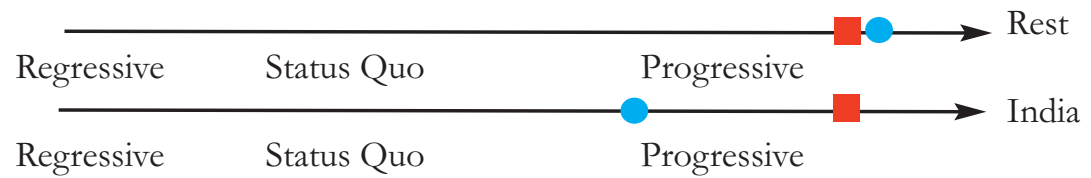

National Adaptation Plans - Two of the secondary players (LDCs and South Africa) desired a progressive outcome on NAPs and a progressive outcome was reached. ${ }^{19}$ In total, two out of two players achieved a satisfactory outcome on NAPs.

\section{Regressive Status Quo Progressive}

REDD+ - Two of the secondary players (LDCs and Japan) desired a progressive outcome on REDD+ and a progressive outcome was reached. ${ }^{20}$ In total, two out of two players achieved a satisfactory outcome on REDD+.

Regressive Status Quo Progressive

Mitigation - One primary player (US) and no secondary players desired a progressive outcome on mitigation and a moderately progressive outcome was reached. ${ }^{21}$ In total, zero out of one player achieved a satisfactory outcome on mitigation.

Regressive Status Quo Progressive

Second Commitment Period - Far and away the least successful issue for all Parties 
involved was the second commitment period of the Kyoto Protocol. Three of the four primary players (China, India and EU) and three of the six secondary players (South Africa, AOSIS and LDCs) desired a progressive outcome. One of the four primary players (U.S.) and two of the six secondary players (Japan and Canada) desired a regressive outcome. ${ }^{22}$ One of the secondary players (Russia) desired a moderately regressive outcome. ${ }^{23}$ Ultimately, a moderately progressive outcome was achieved. ${ }^{24}$ In total, zero out of ten players achieved a satisfactory outcome on the second commitment period.

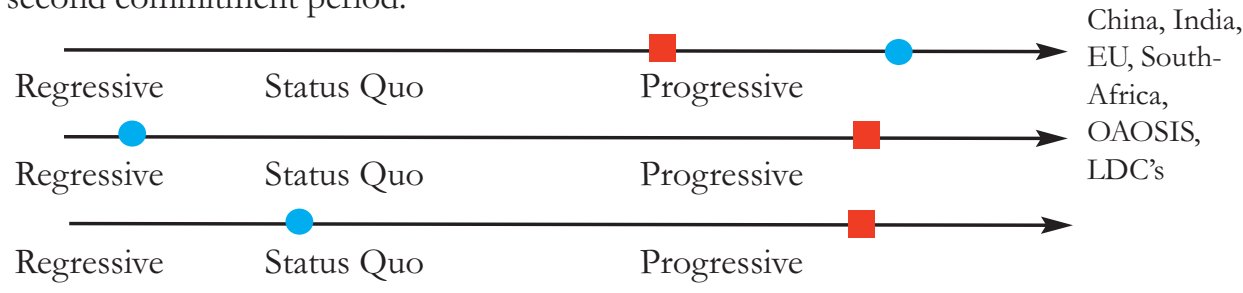

\subsection{Strategy 'Success'}

If we measure the 'success' of the Durban negotiations by examining the degree to which players achieved their desired outcomes on the issues addressed in their opening statements, then we may say that Durban achieved a high degree of success. In their opening statements, the primary and secondary players addressed nine of the ten issues on which decisions were taken at Durban. Of these nine issues, a progressive outcome was desired by all players - and reached - on seven. Of the remaining two issues, mitigation and the second commitment period, mitigation was addressed only by the US (without reference to increased ambition) whereas the second commitment period proved to be one of the most problematic issues at Durban. Not only was it the only issue mentioned by all ten primary and secondary players in their opening statements, it was the only issue where some players stated a desire for a regressive outcome, and it was the only issue where not a single player achieved its desired outcome.

There is an alternative method to measure the 'success' of Durban, namely, to examine the degree to which players were flexible in their positions. For example, imagine two players, player A and player B, are negotiating on the same four issues where both players must take a progressive, status quo, or regressive position. Imagine player A desires progressive outcomes on all four issues and player B desires regressive outcomes on all four issues. If a progressive outcome is reached on two issues and a regressive outcome is reached on two issues, then one may say that these negotiations were equally successful for the two players. If a progressive outcome was reached on all four issues, then the negotiations were successful for player A but unsuccessful for player B, and so forth.

In our case, every single player achieved their desired outcomes on at least half of the issues they addressed in their opening statements. There were no clear 'winners' or 'losers' in this particular respect. Overall, the players addressed an average of 4.2 issues in their opening statements and achieved their desired outcomes on an average 
of 3 issues. Upon closer inspection, the biggest difference was to be found between the primary and secondary players. The primary players addressed an average of 3.75 issues and achieved their desired outcomes on an average of 2.25 issues. The secondary players addressed an average of 4.5 issues and achieved their desired outcomes on an average of 3.5 issues. Thus, one can observe that not only did the secondary players address a larger number of issues overall, they also achieved their desired outcomes on a larger percentage of the issues they addressed. Among the primary players, India and the US were the 'losers' achieving their desired outcomes on two of four issues, the EU ranked second at two of three, and China was the 'winner' with three of four. The rankings of the secondary players were as follows: Canada was the 'loser' having achieved their desired outcome on one of two issues, Japan placed fifth with two of three, AOSIS and Russia ranked fourth with four of five, and the 'winners' were LDCs and South Africa with five of six. If we take all the players together, then the rankings (from lowest to highest) are as follows: Canada, US and India were the 'losers', followed by the EU and Japan in fourth, China ranks third, Russia and AOSIS rank second, and the 'winners' are LDCs and South Africa.

\subsubsection{The Devil is in the Details}

Despite the fact that every primary and secondary player achieved their desired outcomes on at least half of the issues mentioned in their opening statements, their reactions to the decisions taken at Durban ranged from positive to negative. Of all our primary and secondary players, only the EU and South Africa went so far as to call Durban a "success". This suggests that the devil is in the details, and a more indepth, qualitative analysis of players' strategies must be undertaken in order to understand why our players reacted as they did to the Durban outcome.

To illustrate this point, take the issue of the GCF, which enjoyed the highest degree of consensus among our players heading into Durban: eight of the ten primary and secondary players stated their desire for a progressive outcome, and a progressive outcome was achieved. Nevertheless, the GCF negotiations were timeconsuming and painstaking; parties agreed that it should be launched but disagreed about details regarding funding bodies, rules, regulations and so forth. It turns out that details such as these hold importance that cannot be overlooked. For instance, both the US and Japan achieved their desired outcomes regarding the launch of the GCF and the establishment of a global agreement covering all major emitters. However, their demand that the sources of funding for the GCF be independent from UN processes was not met. This 'detail' was important enough to these players to result in reactions to the Durban outcome which were positive overall, but fell short of calling Durban a "success".

The reasoning behind China's and India's less-than-pleased reactions is less complicated. They caved to the demand of both industrialized and least developed nations that they agree to adopt legally-binding commitments (though they succeeded in pushing the start-date back to 2020 from 2015), but failed to win any new references to equity and common but differentiated responsibilities as they had 
demanded (ACT News, 2012). Less straight-forward is the reasoning behind the negative reactions of AOSIS and the LDCs. The strategy of these nations was to throw their weight behind the EU. It is likely that they were aware that this strategy would lead to a sub-optimal result, but they were also aware that throwing their weight behind a more powerful player with a position parallel to their own was the most effective way to secure an agreement that worked in their favor. One may assume that AOSIS and LDCs would be pleased that a global, legally-binding agreement had been reached - indeed, they said it was better than no deal at all - but their demands for a 2015 start-date and a higher level of ambition were important enough to warrant negative reactions.

In conclusion, the extent to which one deems Durban a 'success' depends on the method one uses to assess the negotiations. Constructing players' strategy continuums and evaluating the degree to which countries achieved their desired outcomes on the issues addressed in their opening statements would lead us to the conclusion that Durban was indeed a success. However, the reactions of the players themselves would lead us to a more mixed conclusion. The general frustration of players with the Durban outcome may be attributable to the fact that what is not said is equally as important as what is said (an issue which was not addressed in depth in this paper, but would be an interesting topic for further research); meaning that players will only state their support for the issues they believe have the potential to gain agreement, but desire progress on a larger number of issues which may be ignored. Regardless of whether or not one deems Durban a 'success', the end result indicates that all players exhibited a degree of flexibility in their positions and not a single player obtained the exact outcome they desired.

\section{Recommendations}

One of the most important trends seen at Durban - and as far back as Copenhagen is that only a handful of nations are present at the final negotiation table where the most pivotal decisions are made. Determined not to make the same mistake twice, a majority of the world's nations had thrown their weight behind - or at least allowed themselves to fall into line with - the player with the closest negotiation position to their own. Particularly in the case of the EU Alliance, this was smart strategy, not to mention effective. The importance of geopolitical alliances is not to be underestimated. In the future, we should be aware of the ways in which the formation of new geopolitical alliances (particularly ones which cross traditional negotiation divides) can alter primary players' strategies, such as how the EU Alliance effectively swayed the stance of both BASIC and the US towards the progressive.

At Durban, cracks were exposed within the BASIC bloc, a trend which will play an important role in the next round of negotiations. India has made it clear that they do not intend to sign up for any legally-binding commitments, which likely means it will try to take advantage of loopholes in the wording of the Durban Platform. What remains to be seen is whether or not the remaining members of BASIC follow suit. At Durban, South Africa, Brazil and China (though less so) largely left India to fend 
for itself in the final negotiation session. If this was reflective of genuinely more progressive positions (rather than, say, scapegoating), then there is hope that China, South Africa and Brazil will use their collective weight to influence India's - and by extension BASIC's - position. Whatever their approach, BASIC will need to present a more united front at COP 18 in Qatar or else risk being divided and conquered, as they were in Durban.

One may expect that the role of the EU and their progressive allies will continue to play a very important role in Qatar. In addition to the EU Alliance, the Cartagena Dialogue played an important role at Durban, backing the roadmap championed by the EU, AOSIS and LDCs. The Cartagena Dialogue is a network of "middle ground" countries including the EU and nations from across the development spectrum and almost every negotiation grouping working for progressive and constructive solutions within climate negotiations. At Durban, the 'middle ground' managed to impact outcomes directly because their status as the 'world's majority' was used as political capital to back their common position and pressure the most economically powerful nations to accept more progressive outcomes than they may otherwise have done. At COP 18, the 'middle ground' will continue to play the all-important role of progressively ambitious mediator between BASIC on the one hand and the Umbrella group on the other (the Umbrella group is a loose coalition of non-EU developed countries which includes Australia, Canada, Iceland, Japan, New Zealand, Norway, the Russian Federation, Ukraine, and the US). The task at hand is to balance the equation between the most powerful players by 'trading' favorable outcomes on issues of importance to Umbrella and BASIC in exchange for commitments to legally binding emission reductions. Whether or not this strategy will prove equally effective at Qatar remains to be seen, but the 'middle ground' have proven themselves as a mediating force to be reckoned with.

\section{Conclusions}

In this paper, we utilize a novel mixed-methodological approach to further understanding of the current state of international climate change negotiations. Building on the work of Ward, Grundig and Zorick, this paper sheds light on the 'true' game being played in international climate change negotiations by adopting a modified game theoretic approach which helped the analytic focus to remain on relevant political realities rather than overly complex mathematical models. This was accomplished by utilizing the results of a content and discourse analysis of the Durban negotiations in order to compose a list of players and articulate their strategies. The majority of environmental economics literature assesses international climate change negotiations in terms of their ability (or inability) to produce stable IEAs using complex integrated assessment models. In recent environmental economics literature, these mathematical models have been updated in a variety of fashions in order to account for various political or moral considerations which would normally fall outside the scope of such analyses. We have taken this trend one step further by adopting a truly mixed-methodological approach which replaces overly complex 
mathematical models with a content and discourse analysis of the Durban negotiations round in order to more accurately capture 'reality' and perform a modified game theoretic analysis from this starting point. This paper also builds upon the previous literature by demonstrating the usefulness of mixed qualitative-quantitative analyses for environmental economists, particularly where innately political issues such as international climate change negotiations are concerned.

The most significant findings of this paper may be broadly separated into two categories: the results of the content and discourse analyses and the results of the game theoretic analysis. The main results of the qualitative analyses of the Durban negotiations included that players had modest expectations at the outset of the negotiations, which influenced the issues they addressed in their opening statements. Players emphasized a desire for progressive action on issues which they expected would exhibit a high degree of consensus, such as the operationalization of the Cancun objectives and the GCF, rather than more politically divisive issues such as the second commitment period of the Kyoto Protocol or a legally-binding post-2012 agreement. The qualitative analysis also uncovered evidence of shifting geopolitics, namely the continued break-up of the G77 and China into two main factions: the upand-coming developing countries of BASIC and everyone else. At Durban, this split was made 'official' when BASIC spoke for the first time as a unified negotiation bloc while other G77 and China members such as AOSIS and the LDCs threw their weight behind the EU in support of the EU's roadmap.

Following the qualitative analysis of the Durban negotiations, we performed a quantitative game theoretic analysis where we represented players' strategies in the form of strategy continuums where players' original positions were mapped alongside the Durban outcomes relative to the status quo. The main result of this analysis was that players achieved a high degree of success at Durban; all players achieved their desired outcomes on at least half of the issues they addressed. Of the nine issues addressed in their opening statements, a progressive outcome was desired by all players - and reached - on seven. However, a final qualitative analysis was undertaken whereby players' reactions to the Durban outcome were assessed. The main result was that although players achieved a high degree of success with regard to their stated positions, many players expressed dissatisfaction with the outcome. This implies that vital political concerns underlie strategy, and that qualitative analyses are essential in uncovering them.

Finally, the results of the mixed-method analysis were used to identify important trends from the negotiations and generate recommendations regarding how more progressive outcomes may be reached in the future. The most important trends identified were the cracks exposed within the BASIC bloc and the role of the 'middle ground' alliance. We recommend that the 'middle ground' should maintain its momentum into Qatar and continue to play the role of practical mediator, balancing the equation between BASIC and Umbrella.

These findings underscore the fact that it is difficult to reach clear-cut conclusions when one is analyzing complex phenomena such as international climate change 
negotiations. This paper has contributed to a growing body of literature which demonstrates the usefulness of applying mixed methodological approaches to issues which are regularly approached from an exclusively quantitative perspective. This paper has shed light on the 'true' game being played in international climate change negotiations by articulating player strategies based on their stated positions and analyzing them in conjunction with the results of a qualitative analysis of the negotiations as they actually occurred.

Though a mixed quantitative-qualitative approach allows for more detailed analysis, this strength is also the approach's biggest weakness. The results of an analysis like this one are so specific that they cannot be applied to any other situation; they are not generalizable. In addition, the analysis conducted in this paper was complex; it was both multi-staged and multi-faceted, yet it produced few clear-cut conclusions. It is also necessary to mention that one of the three key components of game theory was missing from this analysis: a consideration of payoffs. In the future, it would be beneficial to explore the possibility of streamlining this methodological approach. This could be accomplished by narrowing the scope of analysis, or simplifying the methodology itself. It would also be beneficial to build upon our approach, for example by creating an economic model which would include a consideration of payoffs, could take into account the political bases of players' strategies, and conduct an analysis which considers how negotiations have actually progressed, including changing geopolitics and global political economy.

\section{Notes}

1 This sentence requires qualification because an in-depth qualitative analyses of international climate change negotiations has been conducted: "Inside UN Climate Change Negotiations: The Copenhagen Conference" by Radoslav S. Dimitrov, Review of Policy Research, Volume 27, Number 6 (2010). However, this article did not fit into the literature review because its methodology did not utilize a content or discourse analytical approach, rather, it was the firsthand account of a government delegate.

2 COP refers to the Conference of the Parties. CMP refers to the Conference of the Parties serving as the meeting of the Parties to the Kyoto Protocol. The CMP meets annually during the same period of the COP. The functions of the CMP relating to the Kyoto Protocol are similar to those carried out by the COP for the Convention. For more information, see the UNFCCC homepage.

3 AWG-LCA stands for the Ad hoc Working Group on Long-term Cooperative Action under the Convention. AWG-KP stands for the Ad hoc Working Group on Further Commitments for Annex I Parties under the Kyoto Protocol. The AWG-KP was established in 2005 with a mandate to consider Annex I Parties' further commitments at least seven years before the end of the first commitment period. The AWG-LCA was established in 2007 with a mandate to focus on key elements of long-term cooperation: mitigation, adaptation, finance, technology and a shared vision for long-term cooperative action.

4 "Legal parallelism" refers to the idea that both developed and developing nations sign an international, legally-binding treaty.

5 "Offering to do the heavy lifting" refers to the EU's proposal at Copenhagen to increase their level of ambition to a 30\% reduction in greenhouse gases by 2020 from $20 \%$ if other countries agree to adopt mitigation targets as well. 
6 For the full text of the Durban Platform, see:

http://unfccc.int/files/meetings/durban_nov_2011/decisions/application/pdf/cop17

_durbanplatform.pdf.

7 The Standing Committee is intended to provide advice and recommendations to the COP on the functioning of the Convention's financial mechanism. At Durban, its functions were clarified and specific activities were identified with regard to improving coherence and coordination in climate change financing; rationalization; mobilization of financial resources; and MRV of support provided to developing countries.

8 It is important to note that we used every player's individual opening statement, except the US because the US did not submit an individual opening statement. Instead, we used the opening statement they aligned themselves with: the UMBRELLA Group.

9 Brazil is defined as a secondary player but has not been included in the quantitative analysis because Brazil did not submit an opening statement.

10 The Cancun objectives that remained to be operationalized included, inter alia, a technology mechanism to promote clean energy and adaptation-related technologies, an adaptation framework to support developing countries, and a Green Climate Fund.

11 The ten issues on which decisions were taken were: a legal outcome, the second commitment period to the Kyoto Protocol, the Green Climate Fund, the Adaptation Committee, the Technology Mechanism, Carbon Capture and Storage in the Clean Development Mechanism, Monitoring, Reporting and Review guidelines, REDD+, National Adaptation Plans, and a mitigation assistance registry for developing nations.

12 The only issue which was not addressed by the primary and secondary players in their opening statements was the issue of Carbon Capture and Storage in the Clean Development Mechanism of the Kyoto Protocol.

13 We defined progressive outcomes as any outcome with served to operationalize or launch new mechanisms or clarify and finalize aspects of existing mechanisms. Any statements which supported these types of outcomes were defined as statements in support of progressive outcomes. We defined regressive outcomes as any outcome which served to remove or reduce existing mechanisms. Any statements which supported these types of outcomes were defined as statements in support of regressive outcomes. We understand that this was a highly qualitative exercise and not everyone will agree with our particular definitions.

14 Statements in support of a progressive outcome on the GCF included being in favor of its "launch" or "operationalization" at COP17.

15 Statements in support of a progressive outcome on MRV included a desire to "finalize MRV processes," being in support of "robust MRV," or supporting scientific reviews.

16 Statements in support of a progressive outcome on Adaptation included favoring the "operationalization" of adaptation mechanisms or the adaptation committee.

17 The Durban Platform established a "process to develop a protocol, another legal instrument or an agreed outcome with legal force" by 2015 to be implemented by 2020. Many players desired a legal outcome before that time, and it remains to be seen what form the legal outcome will take. It is therefore slightly problematic to say this outcome was "satisfactory" for the four players in question, but for the sake of ease of analysis, we decided to ignore these complications during data processing and address them in more depth in the discussion section of this paper.

18 The players who supported a progressive outcome on the Technology Mechanism favored its operationalization. India supported the development of Intellectual Property Rights to facilitate technology transfer and development.

19 Statements in support of a progressive outcome on NAPs included favoring the establishment of guidelines and/or assistance for LDCs to develop NAPs.

20 Statements in support of a progressive outcome on REDD+ included favoring the establishment of "guidelines" or "systems" to better help nations in implementation. 
21 Statements in support of a progressive outcome on mitigation included being "in favor of enabling transparent mitigation by all countries".

22 Statements in support of a progressive outcome on the second commitment period included favoring its "establishment" such that it will be a clear and ratifiable option for all developed Parties to the Protocol. Statements in support of a regressive outcome on the second commitment period included stating "opposition" to the Kyoto Protocol and a refusal to participate in the second commitment period on those grounds.

23 Russia refused to participate in the second commitment period of the Kyoto Protocol, but they did not state outright opposition to the Protocol itself. Russia stated their understanding that other Parties to the Protocol desired a second commitment period, and stated their support for their participation.

24 A case could be made for the fact that since a ratifiable second commitment period was achieved which means this should be called a "progressive" outcome rather than a "moderately progressive" one. However, since only the EU, Norway and Switzerland are currently on board and countries in favor of a progressive outcome demanded more comprehensive participation among developed nations, we have decided to call this a "moderately progressive" outcome.

\section{References}

United Nations Framework Convention on Climate Change. (2011). Retrieved October 8, 2012, from Statements made in connection with COP17/CMP7: http://unfccc.int/meetings/durban_nov_2011/statements/items/6584.php

ACT News. (2012, January 6). What Durban summit really delivered. Retrieved October 8, 2012, from The Canberra Times: http:/ /www.canberratimes.com.au/act-news/what-durban-summit-reallydelivered-20120106-1ucyd.html

Antaki, C. (2008). Discourse Analysis and Conversation Analysis. In P. Alasuutari, L. Bickman, \& J. Brannen, The SAGE Handbook of Social Research Methods (pp. 431-447). Sage Publications Ltd.

Bréchet, T., Eyckmans, J., Gérard, F., Marbaix, P., Tulkens, H., \& van Ypersele, J.-P. (2010). The impact of the unilateral EU commitment on the stability of international climate agreements. Climate Policy, 455-480.

Carraro, C., Eyckmans, J., \& Finus, M. (2005). Optimal Transfers and Participation Decisions in International Environmental Agreements. Fondazione Eni Enrico Mattei, 1-36.

Chestney, N., \& Herskovitz, J. (2011, December 11). New U.N. climate deal struck, critics say gains modest. Retrieved January 30, 2012, from Reuters: http://www.reuters.com/article/2011/12/11/usclimate-idUSTRE7B41NH20111211

Chou, P. B., \& Sylla, C. (2008). The formation of an international environmental agreement as a twostage exclusive cartel formation game with transferable utilities. International Environmental Agreements, 317-341.

Clark, P. (2011, December 5). China throws climate talks into confusion. Retrieved December 2, 2012, from Financial Times: http://www.ft.com/cms/s/0/306566e8-1f4b-11e1-90aa00144feabdc0.html

Doulton, H., \& Brown, K. (2009). Ten years to prevent catastrophe? Discourses of climate change and international development in the UK press. Global Environmental Change, 191-202.

Earth Negotiations Bulletin. (2011). IISD Reporting Services: COP 17. Retrieved October 8, 2012, from International Institute for Sustainable Development: http://www.iisd.ca/climate/cop17/

Eyckmans, J., \& Finus, M. (2003). New Roads to International Environmental Agreements: The Case of Global Warming. Leuven: K.U.Leuven.

Eyckmans, J., \& Kverndokk, S. (2009). Moral concerns on tradable pollution permits in international environmental agreements. Brussels: Hogeschool-Universiteit Brussel.

Farbotko, C. (2005). Tuvalu and Climate Change: Constructions of Environmental Displacement in the Sydney Morning Herald. Swedish Society for Anthropology and Geography, 279-293. 
Forgó, F., Fulöp, J., \& Prill, M. (2005). Game theoretic models for climate change negotiations. European Journal of Operational Research, 252-267.

Gao, Z. (2011). Framing Climate Change: A comparing analysis of Chinese and American elite newspaper coverage on climate change during 2009 Copenhagen Summit. Research Papers, Paper 63.

Hoeffman, J. (2011). Climate change cooperation across the North-South divide - the case of the EU and India. Retrieved December 3, 2012, from

http://www.southasia.ox.ac.uk/_data/assets/pdf_file/0003/37956/Hoeffman,_J_dissertation_ June_2011.pdf

J.A. (2011, December 11). A deal in Durban. Retrieved October 8, 2012, from The Economist: http://www.economist.com/blogs/newsbook/2011/12/climate-change-0

Krippendorff, K. (2004). Content Analysis: An Introduction to its Methodology. Thousand Oaks, California: Sage Publications Inc.

Krukowska, E., \& Morales, A. (2011, December 8). EU Climate Road Map Lures Support From 120 Nations at UN Meeting. Retrieved April 18, 2012, from Bloomberg:

www.bloomberg.com/news/2011-12-08/eu-climate-road-map-lures-support-from-120-nationsat-un-meeting.html

Murray, J. (2011, December 9). Durban deal hangs in the balance as EU roadmap secures fresh support. Retrieved February 13, 2012, from businessGreen:

http://www.businessgreen.com/bg/news/2131365/durban-deal-hangs-balance-eu-roadmapsecures-fresh-support

Osmani, D. (2011). Toward Farsightedly Stable International Environmental Agreements. Environmental Economics and Management, 1-34.

Parker, F. (2011, December 12). Team SA an 'outstanding success'. Retrieved May 14, 2012, from Mail\&Guardian: http://mg.co.za/article/2011-12-12-cop17-team-sa-an-outstanding-successsays-molewa/

Roberts, J. (2011). Multipolarity and the new world (dis)order: US hegemonic decline and the fragmentation of the global climate regime. Global Environmental Change, 776-784.

United Nations Framework Convention on Climate Change. (2012). Retrieved December 6, 2012, from United Nations Framework Convention on Climate Change: http://unfccc.int/2860.php

UNFCCC Conference of the Parties. (2011, December 10). UNFCCC: Decisions Adopted by COP17 and CMP7. Retrieved January 30, 2012, from United Nations Framework Convention on Climate Change:

http://unfccc.int/files/meetings/durban_nov_2011/decisions/application/pdf/cop17_durban platform.pdf

Ward, H., Grundig, F., \& Zorick, E. (2001). Marching at the Pace of the Slowest: a Model of International Climate Change Negotiations . Political Studies, 438-461.

Weingart, P., Engels, A., \& Pansegrau, P. (2000). Risks of communication: discourses on climate change in science, politics, and the mass media. Public Understanding of Science, 261-283.

York, G. (2011, December 5). Globe and Mail. Retrieved February 2, 2012, from China emerges as rock star at Durban climate summit: http://www.theglobeandmail.com/news/world/chinaemerges-as-rock-star-at-durban-climate-summit/article2261157/ 
